\title{
Epidemiology Study of Diphtheria in Indonesia a Case in Solok District in 2011 - 2015
}

\author{
Rosfita Rasyid ${ }^{1}$, Abdiana $^{2}$ \\ rosfitarasyid@med.unand.ac.id \\ Department of Public Health and Community Medicine, Faculty of Medicine \\ Universitas Andalas, Indonesia
}

\begin{abstract}
Diphtheria is one of the main causes of childhood morbidity and mortality in Indonesia, including Solok Districts. While the disease should have been eradicated in the world, in 2015 we found an outbreak in this area with 6 suspected cases. This study aimed to provide the epidemiologic feature of diphtheria in Solok District from 2011 to 2015. To answer the research objective, we have conducted a descriptive epidemiologic study to evaluate all documented cases of diphtheria in primary care. The population was all incidents of diphtheria recorded as cases of diphtheria in Solok Districts. Incidents of diphtheria in Solok Districts were distributed in groups of three sub-districts, which were: Bukit Sundi ( 2 cases), Lemah Gumanti ( 2 cases), Kubung ( 2 cases). The cases were more found in girls ( 4 cases) than boys ( 2 cases). Interestingly, the proportion in non-immunized children is equal to immunized ones. The incidents of diphtheria were kind of isolated cases which need special attention. Public Health Office of Solok Districts should enhance program related to diphtheria included vaccine distribution and storage as well as public education on immunization.
\end{abstract}

Keywords: Epidemiology, Diphtheria, Solok Districts.

\section{Introduction}

Diphtheria is an infection in the upper respiratory system caused by Corynebacterium diphtheriae. Symptoms of the disease may include a sore throat and mild fever. Diphtheria is also characterized by a grey membrane covering tonsils and respiratory tract. Diphtheria occurs worldwide, but incidents of the disease have declined significantly since diphtheria vaccine has been used extensively. The occurrence of diphtheria depends on individual immunity, environment, and access to health care. Diphtheria often occurred to poor people who live in the densely populated area, and access to health service facilities was limited, as well as have low education and knowledge levels. Death generally occurs on people who do not receive immunization. Immunization was given in order to increase the immunity of specific disease actively, so people received the vaccine are protected from the disease [1].

In most cases, diphtheria occurs in 1-10 years old children. The number of diphtheria cases in 2012 was 1,192 cases with mortality number was 76 cases as CFR of diphtheria is 6,38\%. Among 18 provinces reported diphtheria cases, the highest number was found in East Java with 952 cases $(80 \%)$, followed by South Kalimantan and South Sulawesi with 61 cases $(5.1 \%)$ and 50 cases (4.2\%), respectively. According to age group in 2012 data, the figure of the age group of 5-9 months and >14 months showed $30 \%$ and $29.9 \%$ cases, respectively. Furthermore, in 2012 , as many as $47.32 \%$ of cases have received the vaccination [2]. 
Recently, diphtheria has occurred in West Sumatra as well. The disease was reported in two areas, Padang City and Solok Districts. The city officer has declared that the incidents of diphtheria were an outbreak. Therefore, Ministry of Health of the Republic of Indonesia prepared 250 thousand of the vaccine in order to prevent transmission of the dangerous bacteria massively.

Ever since the outbreak on $29^{\text {th }}$ of January $2015,53.52 \%$ children in Padang city had been immunized. It was targeted in February 2015, the first round should have been finished. The second and third round was held in March and September 2015 [3],[4].

Solok is one of the districts located in West Sumatra Province. In this area, it was found that there was one patient died because of the bacteria. In the same time, there were 23 suspected cases hospitalized as three cases had been known as positive. One factor correlated to diphtheria infection is immunization status. Unfortunately, only less than 70\% people of Solok Districts had immunized with diphtheria vaccine. Based on those conditions, research to identify the incidents of diphtheria from 2011 to 2015 needs to be conducted. The results should be useful as data to write policy to prevent the disease to spread these days and so on [5].

As the high incidence of diphtheria in West Sumatra Province, especially in Solok District, a study about diphtheria cases epidemiology correlated to the people, places and time needs to be held. Therefore, policies for diphtheria prevention in the area could be written by the officer. This study aims to find the figure of diphtheria epidemiology in Solok Districts from 2011 to 2015 correlated to the variable of the people, place and time.

\section{Methods}

The design of this study was descriptive research to know the figure of diphtheria epidemiology in Solok Districts between 2011 and 2015. The research was conducted in Solok Districts. Collecting data was started from March to August 2015. Research population was all of the diphtheria cases reported to Infectious Disease Control Subdivision of Public Health Centres in Solok Districts from 2011 to 2015. Research variable consisted of some diphtheria incidents, age, gender, individual immunization status, immunization coverage, place, and time [6],[7].

\section{Results}

\subsection{The Figure of Diphtheria Epidemiology in Solok Districts}

Diphtheria disease is caused by infection by Corynebacterium diphtheria in the upper respiratory system. Symptoms of diphtheria include a sore throat and mild fever with the hallmark of the grey membrane covering tonsils and respiratory tract. ${ }^{1}$ This study attempts to get epidemiology of diphtheria in Solok Districts in 2011-2015 correlated to time, people and place.

\subsubsection{Time}

The distribution of diphtheria cases in Solok Districts from 2011 to 2015 has found with no case recorded in 2011-2014, while 6 cases of diphtheria occurred in 2015. 


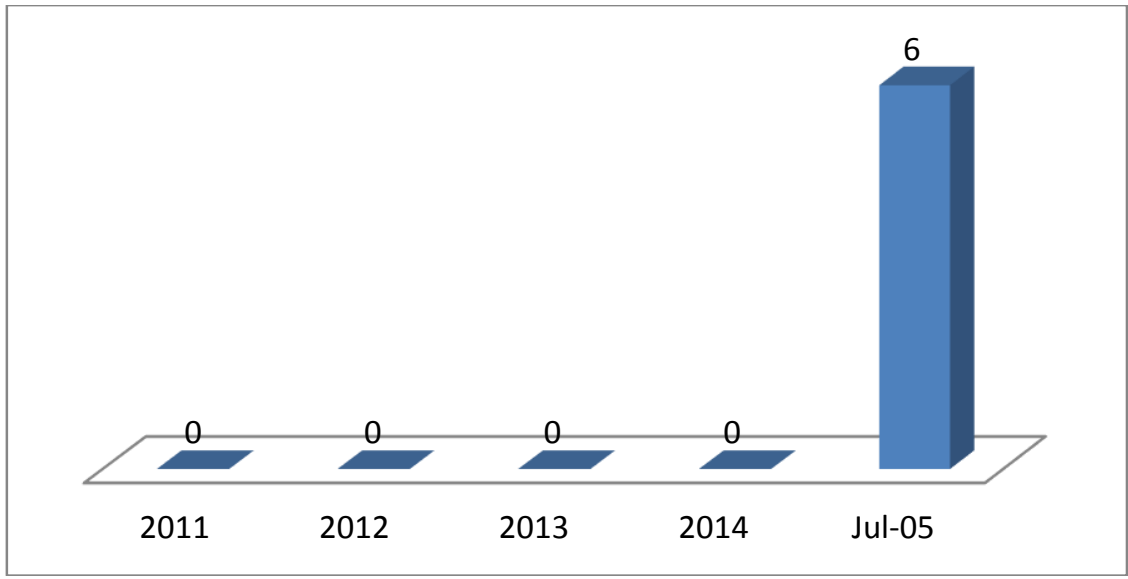

Fig. 1. The cases distribution of diphtheria suspects in Solok Districts in $2011-2015$

According to WHO, diphtheria is an endemic disease in developing countries. In 2015, the 6 of diphtheria cases was declared as an outbreak since from 2011 to 2014 no cases of diphtheria had been recorded in Solok Districts.

\subsubsection{People}

The distribution people: age, gender, place, gender, immunization status. The distribution of diphtheria suspects by age was shown in Figure 2.

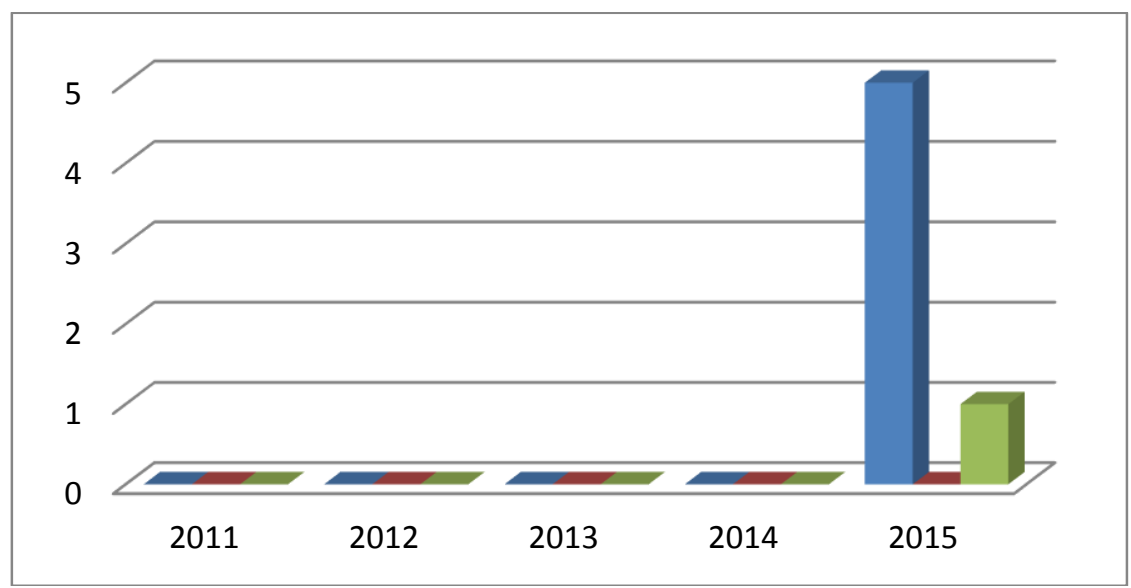

Fig. 2. The distribution of diphtheria suspects by age group in Solok Districts $2011-2015$

The incidents of diphtheria in a group of children $\leq 5$ years old was nil, while only 1 case recorded in a group of children $>5$ years old. The most numerous cases were found in a group of under 5 years old who did complete their diphtheria immunization.

The distribution of diphtheria suspects by gender was presented in Figure 3. 


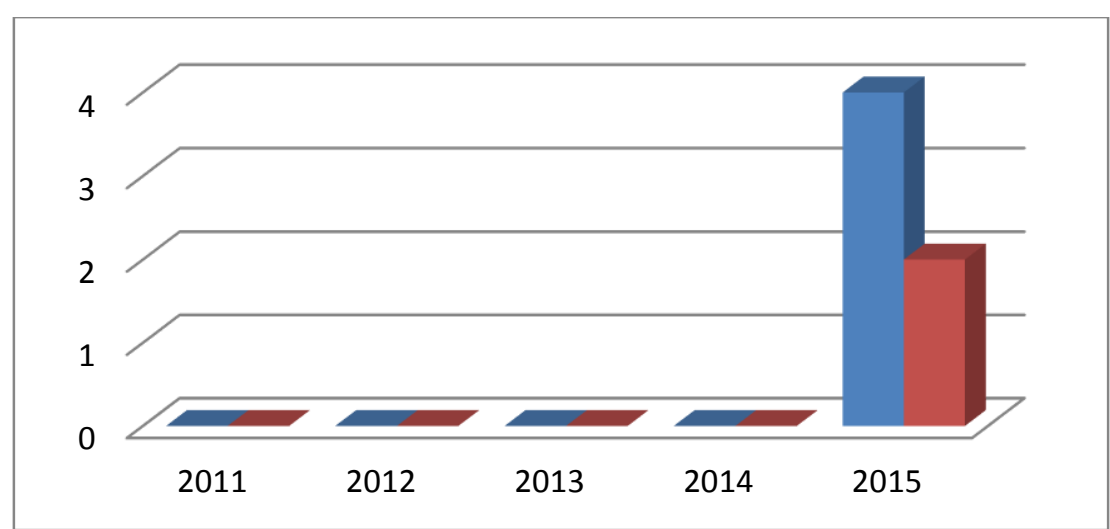

Fig. 3. The distribution diphtheria suspects by gender group in Solok District 2011- 2015

There were no cases of diphtheria recorded in 2011-2014. In 2015, there was number of male diphtheria suspects with 4 people, while there were only 2 females of diphtheria suspects.

The distribution of diphtheria suspects by immunization status was given in figure 4 .

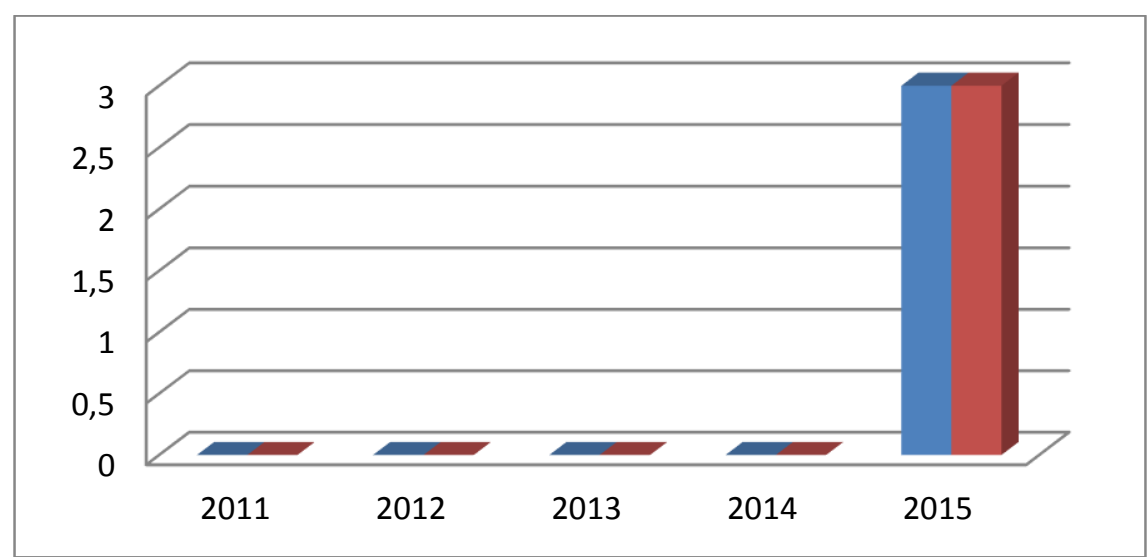

Fig.4. The distribution of diphtheria suspects by immunization status in Solok Districts 2011 2015

In 2015, the number of immunized children suspected diphtheria was compared to the children who did not get an immunization. This is in accordance with the theory which states that the status of diphtheria immunization correlates to the ability of the body to protect itself from diphtheria. Diphtheria infection occurrence was caused by some factors, as immunization is one of the dominant factors of the process. Administrations of 3 doses of diphtheria toxoid in the child will produce antibodies more than average of 0.01 international unit ml (protection as many as $0.01 \mathrm{IU})$. However, the first dose of immunization cannot produce antibody protection to diphtheria.

Until today, the prevention of diphtheria was done through diphtheria immunization routinely of infants from two months old, three times with 1 month of the minimal interval. Diphtheria immunization status of each will affect community protection of the disease in the area because diphtheria vaccination could reduce the number of morbidity of diphtheria. 
Therefore, routine diphtheria immunization in children under five y.o. must be held more effectively and optimally.

\subsubsection{Place}

The incidents of diphtheria based on sub-districts in Solok Districts in 2011-2015 was divided into three groups, Sundi (2 cases), Lembah Gumanti (2 cases) and Kubung (2 cases).

Based on their number of population, Kubung sub-district had the biggest number with 55.303 people. Following Kubung, Lembah Gumanti was the second numerous sub-district with 53.178 people. Far from the numbers before, the last one was Mountain Talang sub-district with 46.738 people.

Diphtheria is the main cause of death in toddlers among diseases with vaccine has provided. Therefore, diphtheria prevention is an important factor affected child mortality.

Immunization coverage is one of the achievement indicators of prevention and elimination. An outbreak of diphtheria occurred in Solok Districts in the year 2015. Public health officer operated a strategy to achieve the immunization coverage target through "Month of Immunization" program in school.

\section{Discussion}

In 2015, the 6 of diphtheria cases was declared as an outbreak since from 2011 to 2014 no cases of diphtheria had been recorded. One factor that could cause the diphtheria outbreak in 2015 is the time of February, March, and April when the season started to change from the rainy season to summer. This climate change might affect people immunity as increase their susceptibility to infectious disease. According to Chin (2000), in a subtropical area, diphtheria occurs only in the months when the temperature is lower.

This study has found that diphtheria happened mostly in sub-district with most numerous population. It is known that the transmission of diphtheria bacterium is easier in a populous area where public housing is dense and unhygienic, such as slum area.

The dense and populous area could make the transmission of the bacteria easier and faster. Numbers of the floor of a house building could also increase the density of an area. As those do not fulfill the health standards, it may cause lower consumption in each room. Besides, it could also cause the transmission of diphtheria among family members easier.

From the previous data, the figure showed a periodicity of diphtheria outbreak. I can be seen when there was a time with no diphtheria infection recorded, meanwhile, in another year, diphtheria occurred and became a serious health problem. This phenomenon may be affected by the immunity of the people in the districts.

It is suggested for public health officer in Solok District to enhanced public care in high-risk areas, increasing diphtheria immunization coverage through all areas in Solok Districts, especially at a group of age under five years old and progressively improving health education for the public related to the importance of immunization diphtheria. 


\section{Conclusions}

This study had found diphtheria epidemiology in Solok Districts from 2011 to 2015 correlated to the place characteristic, the people and the time. The data was collected in three sub-districts (Lembah Gumanti, Bukit Sundi, and Kubung Subdistrict).

a. The incidence of diphtheria in Solok Districts based on age group mostly occurred in children $<5$ years old.

b. There was a bigger proportion of male diphtheria suspects than the female ones in Solok Districts.

The number of cases of immunized patients was equal to non-immunized patients.

\section{References}

[1] Department of Health City. Health Profile. pp: 25-35 (2013).

[2] Ministry of Health Republic of Indonesia. Indonesian health profile. pp: 67-90 (2013).

[3] Ministry of the Health Republic of Indonesia. Public communication center of the secretariat general the ministry of health indonesian. An outstanding incident diphtheria in the city of Padang, Ministry of Health Republic of Indonesia, Jakarta (2012).

[4] Ministry of Health Republic of Indonesia. Guidebooks investigation and handling incredible happenings infectious diseases and food poisoning (guidelines disease edition of epidemiology) revision in 2011. Sub directorate surveillance and an incredible happenings directorate surveillance, immunization, quarantine, and health directorate general for disease control penyehatan environment and health ministry of Indonesia. Ministry of Health Republic of Indonesia, Jakarta (2011).

[5] The City Health Department. Reports on the results of immunization routine the baby in health center. The City Health Department, Padang (2011).

[6] Murti, B. Principles and method of epidemiology research. Gajahmada University Press (2007).

[7] Lemeshow, H. Large sample in health study. First edition. Gajahmada University Press, (1997). 